\title{
Transferência de Renda e a Dinâmica do Crescimento Econômico: Um Modelo de Simulação *
}

\author{
Silvia Harumi Toyoshima \\ Professora - Universidade Federal de Viçosa \\ Endereço para contato: Av. P. H. Rolfs, s/n - Campus Universitário - Viçosa - MG \\ CEP: 36570-000 - E-mail: htsilvia@ufv.br

\section{Evaldo Henrique da Silva} \\ Professor - Universidade Federal de Viçosa - Departamento de Economia \\ Endereço para contato: Av. P. H. Rolfs, s/n - Campus Universitário - Viçosa - MG \\ CEP: 36570-000 -E-mail: ehsilva@ufv.br
}

Recebido em 26 de dezembro de 2011. Aceito em 26 de abril de 2013.

\section{Resumo}

O objetivo do presente artigo foi elaborar um modelo teórico de simulação para verificar efeitos das políticas distributivas de renda sobre a dinâmica do crescimento econômico, de acordo com uma abordagem estruturalista. A simulação tem como referência o modelo de crescimento liderado pelas exportações, do tipo Kaldoriano. Foram traçados cinco cenários contemplando políticas de distribuição de renda, com e sem transferências de renda direta do governo. O cenário que melhor compatibiliza a redistribuição de renda com aumento das taxas de crescimento de longo prazo faz parte do grupo de políticas "sem transferência". No curto prazo, as maiores taxas de crescimento foram obtidas em um cenário do grupo "com transferência de renda". Conclui-se que existe um trade-off entre as políticas de redistribuição, de modo que aquelas que são mais benéficas para o ambiente macroeconômico no curto prazo podem não ser as melhores no longo prazo, e vice-versa.

\section{Palavras-Chave}

distribuição de renda, crescimento econômico, simulação

\begin{abstract}
The purpose of this paper was to elaborate a theoretical model of simulation in order to verify the effects of income transference policies over the economic growth dynamic, following a structuralist approach. The main basis of the simulation is the export-led growth model, of the Kaldorian type. Five scenarios were drawn considering income distribution policies, with and without direct income transfer policy by the government. The scenario that better adjusts the income redistribution with increased rate in the long-term growth is part of the group "without transference" policy. In the short-term the major growth rates were obtained in a group scenario "with income transference". The main conclusion is that there is a trade-off between the redistribution policies in such a way that those which are more beneficial to the macroeconomic environment in the short-term cannot be the best ones in the long-term, and vice versa.
\end{abstract}

\footnotetext{
- Os autores agradecem o apoio financeiro do Programa Cátedras para o Desenvolvimento do IPEA.
} 


\section{Keywords}

income distribution, economics growth, simulation

\section{JEL Classification}

015

\section{Introdução}

Este estudo teve como objetivo desenvolver um modelo teórico de simulação da dinâmica do crescimento, com a finalidade de comparar o impacto macroeconômico de longo prazo de políticas redistributivas alternativas. Uma primeira via compreende políticas que propõem novo perfil de distribuição de renda, a partir de algum tipo de reforma, sem transferência direta de renda pelo governo. Pressupõese que uma renda mais bem distribuída levaria a maior investimento e, consequentemente, à aceleração do crescimento, conforme modelo de Fajnzylber (1989), pertencente à escola da Cepal. A segunda via refere-se às políticas que não promovem, diretamente, nenhum tipo de reforma, visando à distribuição de renda, mas pretendem ser paliativos para minimizar a desigualdade. O exemplo mais significativo desse tipo são os programas de transferência direta de renda do governo, a exemplo do Programa Bolsa Família brasileiro. Com base na teoria cepalina de melhoria na distribuição de renda, parte-se do pressuposto de que esse tipo de programa também teria efeitos positivos sobre o crescimento econômico.

Supõe-se que políticas de distribuição de renda de caráter mais estrutural consistem naquelas que alteram, entre outras variáveis, o perfil da distribuição funcional da renda, o nível de educação e qualificação dos trabalhadores e o grau de competitividade da economia. Por outro lado, políticas de transferência de renda, em princípio, afetam o poder de compra da camada mais pobre da população, não diretamente as variáveis acima mencionadas.

Para comparar os efeitos que uma presumível distribuição de renda causaria ao crescimento e a outras variáveis incluídas no modelo, foram testados cinco cenários diferentes. Mais especificamente, com o trabalho transcrito neste artigo, pretendeu-se responder às seguintes questões: a) é possível encontrar uma associação positiva entre uma renda mais bem distribuída e maior crescimento?; e b) há diferenças substanciais entre os efeitos de uma política de distribuição de 
renda de caráter estrutural e uma política de distribuição de renda, via transferência direta de renda, sobre o crescimento, o nível de investimento, o déficit externo e a utilização de capacidade ociosa?

Ressalta-se que no modelo de simulação não foram considerados os efeitos do crescimento da renda sobre sua distribuição, como no modelo de Fajnzylber (1989). Isso é objeto de pesquisa futura, uma vez que, para a inclusão de tal efeito, seria necessário operar com a matriz de contabilidade social, incluindo o padrão de consumo por estrato de renda.

Crescimento e distribuição de renda são temas que remontam aos clássicos. Contudo, o texto considerado seminal para esse tipo de estudo, que associa diretamente essas duas variáveis, é o de Kuznets (1955), de onde se deriva a famosa e polêmica "Curva de Kuznets". No caso específico da América Latina, a Comissão Econômica para a América Latina (Cepal) encarregou-se, a partir de anos finais de 1940, de explicar o seu subdesenvolvimento, sendo um dos pontos centrais dessa explicação a alta concentração de renda. O texto inaugural dessa escola, o de Prebisch de $1949,{ }^{2}$ criticava a teoria das vantagens comparativas, e admitia ser a industrialização a saída para o desenvolvimento da América Latina. No entanto, já nos anos 1970, houve o reconhecimento de que as economias que se engajaram no processo de substituição de importações e deslancharam seus processos de industrialização não lograram resolver o problema da desigualdade ou de absorção maciça dos excedentes de mão de obra presentes nas economias subdesenvolvidas (Furtado, 1976).

Observa-se, ainda, que nessas economias o indicador mais desfavorável é a desigualdade na distribuição de renda. No caso do Brasil, o país já figurou entre os primeiros no ranking em termos de pior distribuição de renda (World Bank, 2006; Morley, 2001).

1 Deininger e Squire (1997) concluíram que não há evidências de que a hipótese de Kuznets tenha ocorrido para uma amostra de 58 países. Greenwood e Jovanovic (1990) encontraram uma aceleração na desigualdade, quando a economia começa a apresentar taxas aceleradas de crescimento. Aghion et al. (1999) argumentaram que houve uma reversão da tendência de redução das desigualdades nos países da OECD (mais desenvolvidos) nas últimas décadas. Campano e Salvatore (2007) mostraram que a desigualdade aumenta quando há implantação de um setor moderno e diminui conforme a mão de obra migra do setor tradicional para o moderno.

2 Publicado em livro compilado por Bielschowsky (2010). 
Nos anos 1990, a questão da distribuição de renda e o seu papel sobre o crescimento econômico se tornaram um dos principais objetos de estudo em diferentes abordagens teóricas, como a estruturalista, a da nova teoria do crescimento ${ }^{3}$ e a da nova economia institucional. ${ }^{4}$ Neste artigo, a principal referência é a linha de pesquisa hoje dominante dentro da corrente cepalina (Bielschowsky, 2010). Um dos grandes representantes cepalinos dessa nova fase, denominada neoestruturalismo, ${ }^{5}$ Fajnzylber (1989) desenvolveu um esquema analítico, em cujo núcleo se encontra a causalidade circular entre as variáveis crescimento e equidade. ${ }^{6}$

A aplicação de modelos de simulação no estudo das relações causais entre distribuição de renda e crescimento econômico vem despertando o interesse de diversos autores de várias correntes de pensamento. Entre eles, podem ser citados os trabalhos de Jeong e Towsend (2008), Roberts e Zolkiewski (1996), Moreira et al. (2008), Wang e Zhai (1998), Bourguignon et al. (1989) e Boccanfuso et al. (2007). Em relação à abordagem neoestruturalista, que é o fio condutor desta pesquisa, o uso de modelos de simulação na análise do papel das transferências de renda sobre a dinâmica do crescimento econômico, pode ser considerado uma empreitada inédita. Na verdade, o modelo aqui proposto é uma tentativa embrionária de avaliação de políticas redistributivas, levando em conta a natureza multidimensional e as mútuas determinações que imperam no sistema econômico, quando se admite que esse sistema é dinâmico e complexo.

Este artigo está dividido em 4 seções, além das partes de introdução e de conclusão. Na segunda seção, abordam-se as referências teóricas utilizadas na simulação. Na terceira, discute-se a metodologia do trabalho, apresentando-se o modelo de simulação e as variáveis utilizadas. Na quarta, dedica-se à análise dos resultados da simulação. Esses resultados foram extraídos de cinco cenários de mudanças exógenas, que supostamente representam políticas de redistribuição de renda dentro um contexto coerente com a economia brasileira.

\footnotetext{
Cf., por exemplo, Aghion et al. (1999).

Cf., por exemplo, trabalhos de Aghion et al. (2007).

Cf. Bielschowsky $(2004,2010)$.

6 Da mesma forma, autores mais inclinados à vertente neoclássica, como Aghion et al. (1999), com explicação teórica diferente, também defendem que uma mudança estrutural no perfil de distribuição de renda leva a maior crescimento.
} 


\section{Crescimento e Distribuição de Renda}

Existem alguns modelos teóricos que defendem a associação positiva entre crescimento e distribuição de renda, contrariando modelos apoiados em Kuznets (1955), por exemplo, que supõem um trade off entre essas duas variáveis, em países que se encontram em fases iniciais do processo de industrialização.

Os primeiros teóricos da Cepal, ao contrário, sempre associaram melhor distribuição de renda com maior dinamismo, em termos de crescimento, via desencadeamento do processo de industrialização. No entanto, apenas em finais da década de 1980, as complexas interações entre distribuição de renda e crescimento econômico foram colocadas no centro de um esquema teórico formulado originalmente por Fajnzylber (1989).

De acordo com Fajnzylber (1989), o crescimento favorece a equidade, à medida que a elite dominante pode aceitar mais facilmente algum processo de distribuição de renda, se a economia estiver em fase de crescimento econômico. Isso não significa que a renda, automaticamente, será distribuída sempre que a economia crescer. Por outro lado, a equidade favorece o crescimento de duas formas: em primeiro lugar, porque melhor distribuição de renda faz com que a população como um todo tenha um sentimento de pertencer à sociedade, o que torna possível demandar maiores sacrifícios para a redução do consumo no curto prazo, em prol de projetos de crescimento de longo prazo; e, em segundo, porque maior equidade permite um padrão de consumo compatível com uma taxa mais acelerada de crescimento e um nível de investimento mais eficiente.

A imitação do padrão de consumo dos países desenvolvidos é uma característica das economias subdesenvolvidas que, dada a concentração de renda, possuem uma pequena elite rentista que consome produtos considerados de luxo. A internalização dessa produção nessas economias não é feita de forma eficiente pela falta de escala.

Uma renda mais bem distribuída, assim, levaria a um padrão de consumo da sociedade mais austero, o que, por sua vez, elevaria o crescimento por duas razões: a primeira, pelo consumo mais frugal da sociedade como um todo, permitindo maior poupança e, consequentemente, maior investimento; e, segundo, pelo fato de a pro- 
dução de bens básicos apresentar menor relação capital/produto, o que implica taxas de crescimento maiores, com determinado nível de investimento.

O sistema industrial e a competitividade internacional estão diretamente conectados com o crescimento, sendo causa e efeito dessa variável. O argumento utilizado por Fajnzylber (1989) é que o crescimento permite incorporar novas gerações de equipamentos e produtos, elevando a produtividade do sistema industrial e melhorando a competitividade em nível internacional. A produção de novos bens, com a ampliação do mercado interno, induz a aprendizagem industrial e tecnológica. Um sistema industrial mais competitivo, por sua vez, induz maior crescimento.

Já o impacto positivo do sistema industrial competitivo internacionalmente sobre a equidade ocorre por meio de: criação de pequenas e médias empresas inovativas e competitivas; maior qualificação da mão de obra; crescimento mais rápido do emprego associado com o dinamismo do mercado internacional; elevação da produtividade e das remunerações; universalização da educação; e, por fim, pela propagação da lógica empresarial. Ou seja, esse impacto ocorre por meio do alcance de uma competitividade verdadeira e não espúria, caso daquela que tem como base os baixos salários.

O ponto mais polêmico do esquema exposto refere-se a se um padrão de consumo mais austero que gera, em primeiro lugar, maior poupança e, em segundo, uma produção com relação capital/produto menor. Ambas induziriam maior crescimento. A primeira tem gerado polêmica na economia brasileira, desde o período do milagre, em finais da década de 1960 e início da de 1970, uma vez que maior crescimento redundou em piora na distribuição de renda. ${ }^{7}$ A justificativa do governo da época para tal fenômeno ficou conhecida como a "teoria do bolo", que defende a ideia de que era necessário um processo de concentração de renda inicial, a fim de elevar a poupança e, consequentemente, o investimento, acelerando o crescimento econômico. Numa segunda etapa, o maior nível de renda decorrente desse processo seria distribuído, beneficiando toda a população (Gremaud et al., 2009). Teoricamente, essa tese pode encontrar suporte na primeira geração de pós-keynesianos, representados por Kaldor (1956), Robinson (1956) e Pasinetti (1962). De acordo com

7 Cf. estudos de Langoni (1973) e Bonelli e Ramos (1993).

Est. Econ., São Paulo, vol. 43, n.3, p. 525-555, jul.-set. 2013 
Lima (1999), essa geração supunha plena utilização da capacidade produtiva em seus modelos macroeconômicos. Infere-se, então, que qualquer aumento do investimento só poderia ocorrer com aumento da poupança. Aghion et al. (1999) identificam três argumentos na literatura que defendem a ideia de que desigualdade gera maior crescimento: $1^{\text {o}}$ ) a hipótese kaldoriana de que a propensão a poupar dos ricos é maior do que a dos pobres; $2^{\circ}$ ) a das indivisibilidades do investimento, o que envolve um montante considerável de "sunk costs", requerendo a concentração de rendas individuais; e $3^{\circ}$ ) a ideia de James Mirrlees ${ }^{8}$ de que há um trade-off entre equidade e eficiência, à medida que os empregados se sentirão desencorajados a desempenhar melhor, caso não recebam salário compatível com seu esforço. Ou seja, tais fundamentos teóricos contrariam a visão de Fajnzylber (1989).

Em relação ao segundo ponto, os argumentos de Furtado (1968) foram os mesmos apresentados por Fajnzylber (1989), de que a alta concentração de renda induz a elevada relação capital/produto, pelo fato de o mercado interno ser restrito, reduzindo a taxa de crescimento econômico. Uma das razões para isso é que a produção de bens de capital somente seria possível com preços elevados desses bens, pela baixa demanda, e a outra se deve ao fato de os bens duráveis de consumo - bens supérfluos demandados pela elite - possuírem uma relação capital/produto alta. A produção tanto de bens de capital como de bens duráveis de consumo, assim, reduziria a taxa de crescimento.

Esse argumento, contudo, foi contestado por Tavares (1982), que reviu a tese da estagnação - defendida por ela mesma anteriormente - em razão do excelente desempenho da economia brasileira no período do "milagre econômico". Segundo a autora, o rápido crescimento da economia naquele período teria sido possível porque, provavelmente, a relação capital/produto não havia aumentado. Mesmo investindo nos setores acima mencionados, cada novo lote de equipamentos tende a ser poupador de capital em termos de custos e de produtividade. Assim, deve-se considerar que os efeitos do progresso técnico sobre os novos equipamentos podem manter, ou até reduzir, a relação capital/produto, contrariando a tese de que haveria redução do crescimento.

8 "An exploration in the theory of optimum income taxation", Review of Economics Studies, 1971, p. 175-208. 
Por outro lado, teóricos mais inclinados à vertente neoclássica, como Aghion et al. (1999), apresentam outra linha de argumentação para defender a existência de relação positiva entre distribuir renda e crescer. Partem do pressuposto neoclássico de que o investimento em capital apresenta retornos decrescentes. No entanto, supõe que o mercado de capital é imperfeito, ou seja, que a capacidade de tomar empréstimos junto às instituições financeiras é diferenciada entre os indivíduos. Nessa situação, o produto agregado não é gerado pelo estoque de capital agregado - como é a hipótese do modelo neoclássico tradicional - mas pela soma dos capitais individuais. Como a capacidade de investimento é diferenciada entre os agentes, sendo maior para os ricos, a produtividade marginal do capital destes é menor; para os pobres, por outro lado, essa produtividade é maior. Assim, deduz-se que, quanto mais desigual é a distribuição de renda, e, consequentemente, da riqueza, menor é a taxa de crescimento, uma vez que os investimentos serão feitos mais por aqueles cuja produtividade marginal do capital é menor. Os autores concluem, então, que melhor distribuição de renda está atrelada a maiores níveis de investimento do conjunto da economia, gerando maiores taxas de crescimento econômico, tese esta que reforçam com evidências empíricas que apontam uma alta correlação entre as taxas de investimento e as taxas de crescimento econômico.

Esse debate demanda estudos adicionais que verifiquem se a distribuição de renda induz aumento das taxas de investimento, promovendo a elevação das taxas de crescimento econômico. Do ponto de vista teórico, é plausível a hipótese de que melhor distribuição de renda produz efeitos quantitativos e qualitativos que impactam positivamente a taxa de investimento, firmando o elo entre a redistribuição de renda e o crescimento econômico.

Desse modo, a proposição do trabalho é simular os impactos de diferentes políticas redistributivas de renda sobre determinadas variáveis macroeconômicas.

\section{Equações do Modelo de Simulação}

O modelo proposto é constituído por um sistema de equações lineares e não lineares, parte delas contendo valores autorregressivos, parâmetros de ajustamento e efeitos de realimentação circular (feed- 
back loop), o que inviabiliza a obtenção de uma solução matemática para a interpretação dos resultados produzidos por esse modelo. Em vista disso, foi empregada a técnica de simulação numérica.

Para a execução do exercício de simulação, foram definidos cinco cenários representativos do impacto da pressuposta distribuição de renda sobre o crescimento econômico. Esse exercício de simulação foi realizado utilizando-se o sistema SIMULINK/MATLAB.

A complexidade das interações entre distribuição de renda e crescimento econômico, apresentada na seção anterior, envolve um número significativo de determinações de natureza qualitativa e quantitativa que demandarão estudos empíricos exaustivos para transformá-las em equações matemáticas. Nesta seção será apresentado um modelo de simulação relativamente simples, mas representativo de um esforço na direção do entendimento das complexas relações dos impactos da distribuição de renda sobre o crescimento econômico. $\mathrm{O}$ objetivo desse modelo é avaliar os efeitos macroeconômicos de curto e longo prazo das políticas distributivas.

As equações do modelo são compostas de variáveis contínuas e discretas, cujo tempo amostral se refere a períodos consistentes com uma escala anual. Assim sendo, as taxas de variação e as equações de determinações são modeladas para períodos anuais. As tendências de longo prazo, por sua vez, apresentam-se como resultados de interações complexas do modelo, e somente poderão ser analisadas com a execução do exercício de simulação.

O bloco principal de equações versa sobre a determinação do valor da produção nacional. A formulação desse bloco foi inspirada no modelo de crescimento liderado pelas exportações do tipo kaldoriano. Nesse modelo, as exportações carregam o componente autônomo fundamental para a determinação do nível de produção. As exportações mundiais representam esse determinante autônomo fundamental da demanda final, e as exportações nacionais resultam da participação (market share) da economia nacional no valor das exportações mundiais.

Os fatores determinantes do market share das exportações nacionais são formados por um mix de determinações endógenas e exógenas, conforme mostrado no bloco de equações relativo à competitividade externa. 
Os blocos de equações do modelo de simulação e os pressupostos subjacentes são descritos a seguir:

a) Bloco principal - determinantes do nível de renda e do emprego

Este bloco versa sobre a determinação da produção nacional. As Equações (1), (2), (3), (4), (5) e (6) formam uma versão "exportled growth model" do tipo kaldoriana. Quase todos os componentes da demanda final, exceto as exportações, são plenamente induzidos pelo nível de renda (incluindo o grau de utilização da capacidade produtiva). ${ }^{9}$

$$
\begin{aligned}
& Y=C F+I P+I G+C G+X-M \\
& C F=b_{1}(Y-t Y+T F) \\
& I P=v Y \\
& I G=\left(1-b_{2}\right)(T-T F) \\
& C G=b_{2}(T-T F) \\
& X=s X^{m} \\
& M=m Y \\
& \dot{v}=a_{k}(u-\widetilde{u}) \\
& T=t Y \\
& u=Y / Y P \\
& Y P=\sigma \mathrm{k} \\
& \dot{K}=I P+I G-\delta K
\end{aligned}
$$

em que

$Y=$ nível de renda;

$\mathrm{CF}=$ consumo das famílias;

9 As variáveis com sobrescrito “.” e “^” representam a derivada e a taxa de variação em relação ao tempo, respectivamente. 
$\mathrm{CG}=$ consumo do governo;

$I P=$ investimento do setor privado;

$I G$ = investimento do governo;

$T F=$ transferências governamentais para as famílias;

$X=$ exportações nacionais;

$X^{m}=$ exportações mundiais;

$M=$ importações nacionais;

$T=$ renda do governo;

$Y P=$ produto potencial;

$K$ = estoque de capital;

$b_{1}=$ propensão marginal a consumir das famílias;

$b_{2}=$ propensão marginal a consumir do governo;

$u$ = grau de utilização da capacidade produtiva;

$s=$ market share das exportações nacionais;

$m=$ coeficiente de penetração das importações;

$v=$ propensão marginal a investir do setor privado;

$t=$ taxa de imposto (carga tributária);

$\sigma=$ relação produto/capital;

$\delta=$ taxa de depreciação; e

$a_{k}=$ parâmetro do modelo

Este bloco do modelo é composto por algumas variáveis cujas mudanças podem ser operadas pelas políticas fiscais. A transferência de renda para as famílias (TF) é uma delas, a qual comporá um dos cenários analisados. Outro componente suscetível de alteração, por 
meio de políticas públicas, mas de natureza estrutural, é a relação capital/produto $(\sigma)$, que foi escolhido também para compor um dos cenários a ser analisado. Esse componente pode sofrer mudanças de longo prazo em decorrência de políticas de redistribuição de renda, tendo em vista a hipótese, no modelo de Fajnzylber (1989), de que uma melhor distribuição de renda opera como um fator de estímulo à produção de setores menos intensivos em capital.

\section{b) Bloco da dinâmica competitiva - determinantes de s e $m$}

Neste bloco estão sumarizadas as equações que contemplam a dinâmica da competitividade externa, sendo essa dinâmica regida pela equação replicadora (Equações 13 e 14), utilizada frequentemente nos modelos evolucionários de dinâmica industrial como substituta da modelagem tradicional (modelos neoclássicos de concorrência de longo prazo). Utiliza-se essa equação frente à hipótese de que a concorrência é um fenômeno multidimensional e de que a seleção das unidades mais competitivas se dá em termos de expansão do market share dessas unidades, sendo esse um processo complexo e, por conseguinte, relativamente lento (conforme o valor dos parâmetros $\phi$ ).

$$
\begin{aligned}
& \dot{s}=\phi_{1}(e c-1) s \\
& \dot{m}=\phi_{2}(\mathrm{p}-1) \mathrm{m} \\
& p=1 /[m+(1-m) e c] \\
& e=[(P E / P D) E]^{\beta_{1}}[L]^{\beta_{2}}[I]^{\beta_{3}} \\
& e c=e /(u / \bar{u})^{2} \\
& L D \int\left(\sum_{t=1}^{4} \rho_{t} \hat{Y}\right) Y_{0} \\
& L E=\int \hat{Y}^{m} Y^{m} \\
& L=\left[\frac{\log (L D)}{\log (L E)}\right] / \Theta_{\Theta}^{\log (L D)-\log (L E)}
\end{aligned}
$$




$$
\begin{aligned}
& I=\left[\frac{I P+I G-\delta K}{Y}\right] / I^{m} \\
& \dot{P D}=\alpha(u-\bar{u})
\end{aligned}
$$

em que

$P E=$ nível de preços externos;

$P D=$ nível de preços interno;

$E=$ taxa de câmbio;

$L D=$ aprendizagem tecnológica acumulada na economia nacional;

$L E=$ aprendizagem tecnológica acumulada em uma economia representativa, cujo nível de renda inicial é igual ao da economia nacional $\left(Y^{m}=Y\right.$ no tempo 0$)$;

$e=$ nível de competitividade da indústria nacional;

$I^{m}=$ média mundial da taxa de investimento;

$Y^{m}=$ média mundial do PIB;

$\tau=$ tempo;

$\rho_{t}=$ valor da ponderação $\left(\tau_{1}=0.2 ; \tau_{2}=0.3 ; \tau_{3}=0.3 ; \tau_{4}=0.2\right) ; \mathrm{e}$

$\phi_{i} ; \beta_{i}, \Theta=$ parâmetros do modelo, sendo $\beta_{1}>0 ; \beta_{2}>0 ; \beta_{3}>0$.

As Equações (18) e (19) captam o processo de aprendizagem tecnológica, que é supostamente cumulativa e dependente do nível de produção. Essa cumulatividade é captada pela integral das variações observadas no nível de renda interna $(L D)$ e externa $(L E)$. Admitese, ainda, o efeito spillover, determinado pela distância entre $L D$ e $L E$ (denominador da Equação 20). Essas equações representam uma versão do tipo evolucionária do mecanismo kaldoriano de causação circular e cumulativa entre o crescimento econômico e a competitividade externa. 
Nota-se que a função spillover depende do parâmetro $\Theta$. É plausível a hipótese de que o valor desse parâmetro é específico de cada país, estando ele diretamente ligado às competências tecnológicas nacionais. Políticas redistributivas focadas na redução das desigualdades educacionais podem aumentar as competências tecnológicas do país, gerando aumento do efeito spillover no longo prazo. Um dos cenários foi modelado para captar esse efeito. Nesse cenário o parâmetro $\Theta$ aumenta paulatinamente até atingir o dobro do valor original (igual a um).

A Equação (17) amplia as dimensões da competitividade para captar o efeito das mudanças no grau de utilização da capacidade produtiva sobre o prazo de entrega no exterior por parte das firmas nacionais. Ela é, obviamente, uma versão bastante estilizada desse efeito.

A Equação (21), por sua vez, capta o efeito direto dos investimentos sobre a competitividade externa. A taxa de investimento é tradicionalmente utilizada como variável proxy da taxa de renovação do estoque de capital, mas pode também afetar outras dimensões da competitividade externa, a exemplo da expansão dos canais de distribuição e das vias de transporte.

Finalmente, a Equação (22) é uma versão bastante simples das equações fundamentadas na hipótese do mark up flexível, em que se supõe que as firmas estejam dispostas a rever seus níveis de mark up perante uma situação de forte expansão ou de forte retração na demanda.

c) Bloco do setor externo - determinantes de E

$$
\begin{aligned}
& \dot{E}=\rho E(\dot{R} / R) \\
& \dot{R}=M-X-F E \\
& F E=\gamma_{1} \hat{Y}+\gamma_{2}(X-M / Y)+\gamma_{3}(j-\bar{J}) \\
& \dot{R}=\int \dot{R} \mathrm{dt}
\end{aligned}
$$


em que:

$\dot{R}=$ saldo em conta corrente (sinal invertido);

$F E=$ fluxo do capital externo;

$j=$ taxa de juro interna;

$\bar{J}=$ taxa de juro externa; e

$\gamma_{i}=$ parâmetros do modelo.

O conjunto de determinações desse bloco é autoexplicativo, salvo aquelas que formam a Equação (23). Essa equação foi estipulada de forma que as oscilações do saldo comercial fossem transmitidas para o valor da taxa de câmbio, mas numa forma amortecida, de modo que as oscilações na taxa de câmbio fossem ajustadas dentro de intervalo empiricamente consistente (no presente caso, entre 0,7 e 2) para uma média igual à unidade.

\section{Resultados do Exercício de Simulação}

O modelo foi inicialmente calibrado, tendo como referência o desempenho geralmente observado no mundo real, com ênfase na economia brasileira. No presente caso, a calibração ficou centrada na observação de que as taxas de crescimento de longo prazo da economia nacional giram em torno de 3 a 5\% a.a. Os valores dos parâmetros foram definidos de modo a haver um cenário básico (benchmark) que produzisse uma taxa média, variando próximo a $3.5 \%$ a.a, ${ }^{10}$ compartilhada com tendências de queda do market share das exportações e de aumento do coeficiente de importação, com estabilização do déficit externo (\% do PIB) e das taxas de investimento. Esse cenário serviu de base para as análises do impacto das políticas de redistribuição de renda. ${ }^{11}$ Esse e os demais cenários podem ser descritos nos seguintes termos:

\footnotetext{
${ }^{10}$ Os parâmetros cujos valores podem ser inferidos a partir das estatísticas macroeconômicas foram designados com valores dentro de uma margem condizente com as estatísticas brasileiras.

${ }^{11}$ Os valores dos parâmetros se encontram no Anexo A.
} 
Cenário l: É definido de acordo com a suposição de que não há qualquer tipo de política distributiva de renda. Esse cenário cumpriu a função de benchmark, resultante da calibração do modelo (parâmetros e valores iniciais especificados no Anexo A), que gerou trajetórias temporais com padrões representativos da economia brasileira.

Cenário 2: Supõe a existência de uma política distributiva da renda, via transferência de renda do governo para as famílias, financiada com recursos orçamentários, mas sem ocorrência de déficit fiscais. A transferência de renda ocorre de forma paulatina, aumentando de 5\% ao ano até atingir 20\% do total da arrecadação. No mais, os valores dos parâmetros e os valores iniciais seguem especificações do Anexo A.

Cenário 3: Supõe a existência de uma política distributiva de renda sem transferência de renda do governo, a exemplo da política de aumento real do salário mínimo, que produz efeitos na composição da demanda final, de modo a reduzir a relação capital/ produto (valor inverso do parâmetro $\sigma$ na Equação 1l) de 2 para 1,5. Essa mudança ocorre paulatinamente ao longo de um período de cinco anos. No mais, os valores dos parâmetros e os valores iniciais seguem especificações do Anexo A.

Cenário 4: Supõe a existência de uma política distributiva de cunho estrutural, focada na redução das desigualdades educacionais, a qual reflete diretamente sobre a produtividade da mão de obra e a competitividade da indústria nacional. O efeito dessa política foi simulado com o aumento da capacidade absortiva (spillover) da indústria nacional (parâmetro $\Theta$ na Equação 20). Esse aumento ocorre de forma paulatina, levando vinte anos até que o valor do parâmetro seja dobrado. ${ }^{12}$ No mais, os valores dos parâmetros e os valores iniciais seguem especificações do Anexo A.

Cenário 5: Supõe a existência de uma política distributiva da renda via transferência de renda para as famílias, sendo essa financiada exclusivamente com déficit fiscal. Esse déficit ocorre de forma paulatina, aumentando $5 \%$ ao ano, até atingir o equivalente a $20 \%$ do total de arrecadação. Nesse cenário, foi incorporada uma regra que estipula o quanto esse déficit afeta os investimentos. Em cada período, a propensão a investir comporta uma perda de valor induzida pelo aumento das taxas de juros (aumento esse decorrente do déficit público), nos seguintes termos: $-\dot{v}=0,1 * T F / Y E$. Essa variação negativa (efeito crowding out) é somada ao valor induzi-

12 Por simplificação, foi adotada a hipótese de que essa mudança não altera a composição do vetor de demanda final. 
do pelo grau de utilização da capacidade produtiva (Equação 8). No mais, os valores dos parâmetros e os valores iniciais seguem especificações do Anexo A.

Comparando essas alternativas de políticas redistributivas de natureza fiscal (transferência pública), social (política salarial) e estrutural (reforma educacional), evidenciam-se mudanças nas trajetórias simuladas que podem ser visualizadas nas figuras abaixo.

As mudanças no desempenho da produção nacional foi o primeiro impacto analisado. Observa-se, na Figura 1, que a transferência pública de renda para as famílias sem endividamento do governo (Cenário 2) é uma política que reduz a taxa de crescimento de longo prazo da economia. Opostamente, uma política redistributiva que altera a composição da demanda final (Cenário 3) é a que mais favorece o crescimento de longo prazo. A política de transferência de renda do governo para as famílias com déficit público (Cenário 5) tem impacto acentuadamente maior nos primeiros anos após a adoção da política. Isso indica que, no curto prazo, e sem contar com o impacto em outras dimensões do desempenho macroeconômico, esse tipo de política deveria ter prioridade sobre as demais.

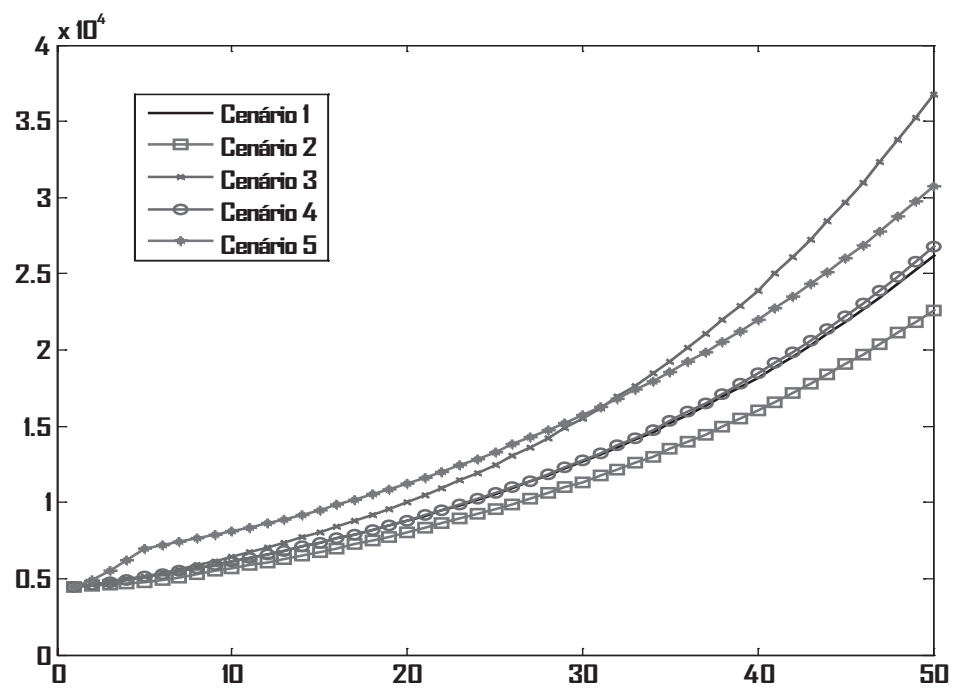

Figura 1 - Trajetória simulada do produto nacional 
A análise da estrutura do modelo permite algumas conclusões sobre essas mudanças. Com relação às políticas de transferência de renda sem déficit fiscal (Cenário 2), o resultado acima decorre da interação de efeitos opostos. De antemão, a transferência de renda para as famílias $(T F>0)$ impacta positivamente o multiplicador de gastos. Contudo, essa política afeta negativamente os investimentos do governo, produzindo um efeito oposto sobre a demanda final, além de afetar negativamente a taxa de investimento do conjunto da economia. Esse efeito atinge diretamente um dos componentes da competitividade externa, fortalecendo as tendências de queda do market share das exportações e de aumento do grau de penetração das importações.

No Cenário 3, a queda da relação capital/produto favorece o aumento da capacidade produtiva do estoque de capital, reduzindo o grau de utilização da capacidade produtiva. De imediato, esse efeito é perverso para os investimentos, mas atinge a competitividade externa, limitando as importações e impulsionando as exportações. Os resultados mostrados na Figura 1 indicam que os efeitos da competitividade, no longo prazo, compensaram a tendência de queda da taxa de investimento nos primeiros anos após a implantação da política.

Os resultados do Cenário 4 são, em princípio, um contrassenso, pois os avanços no nível de qualificação da mão de obra têm sido várias vezes apontados como caminho para o aumento da competitividade externa e do crescimento econômico. Essa dúvida desaparece quando se leva em conta o fato de que outras variáveis do crescimento (a exemplo da demanda por investimento, que depende do grau de utilização da capacidade produtiva) e outras dimensões da competitividade (a exemplo da taxa de investimento), que não dependem da qualificação da mão de obra, estão presentes no modelo. Essas dimensões não foram afetadas pelas políticas representadas nesse cenário, tornando inócuos os efeitos dessas políticas sobre o crescimento econômico.

No Cenário 5, provavelmente, ocorreu um movimento inverso ao que foi observado no Cenário 3. A redistribuição com transferência e déficit impactou fortemente sobre a atividade econômica nos primeiros anos após a implantação da política, favorecendo os investimentos. Mas, no longo prazo, o efeito crowding out, somado à perda de com- 
petitividade, impediram a sustentação de taxas de crescimento mais elevadas, de modo a impedir que nesse cenário fossem geradas as maiores taxas de crescimento de longo prazo.

Nas Figuras 2 e 3 é indicada a evolução temporal de dois indicadores importantes da competição: a participação das exportações brasileiras no total das exportações mundiais (market share das exportações) e o coeficiente de importação. As trajetórias representadas nessas figuras indicam que políticas redistributivas, afetando a composição da demanda final em favor dos setores menos intensivos em capital, promovem o aumento da competitividade externa no longo prazo. Políticas de transferência de renda do governo para as famílias, seja com ou sem déficit fiscal (Cenários 2 e 5, respectivamente), reduzem a competitividade externa, mas por modos diferentes.

O Cenário 2 provoca uma queda substancial nas taxas de investimentos por conta da queda no grau de utilização da capacidade produtiva nos primeiros períodos da simulação e, principalmente, por conta da queda da propensão a investir do governo. Por sua vez, o Cenário 5 produz um excesso do grau de utilização nos primeiros períodos da simulação, o que compromete a competitividade externa nesses períodos, mas o impacto maior vem do aumento do déficit externo.

Tudo indica (fato esse confirmado na Figura 6) que a política representada no Cenário 3 promove o aumento da competitividade externa, via aumento da taxa de crescimento da capacidade produtiva da economia, aliviando as pressões da produção sobre a capacidade produtiva (Equações 10 e 11). Com isso, a economia torna-se mais competitiva, via mecanismo de preços (Equações 16 e 22) e via aumento da oferta externa (Equação 17).

Nos demais cenários, a perda de competitividade pode ser atribuída à diminuição dos investimentos públicos (Cenário 2) ou ao efeito crowding out, reduzindo os investimentos privados (Cenário 5). 


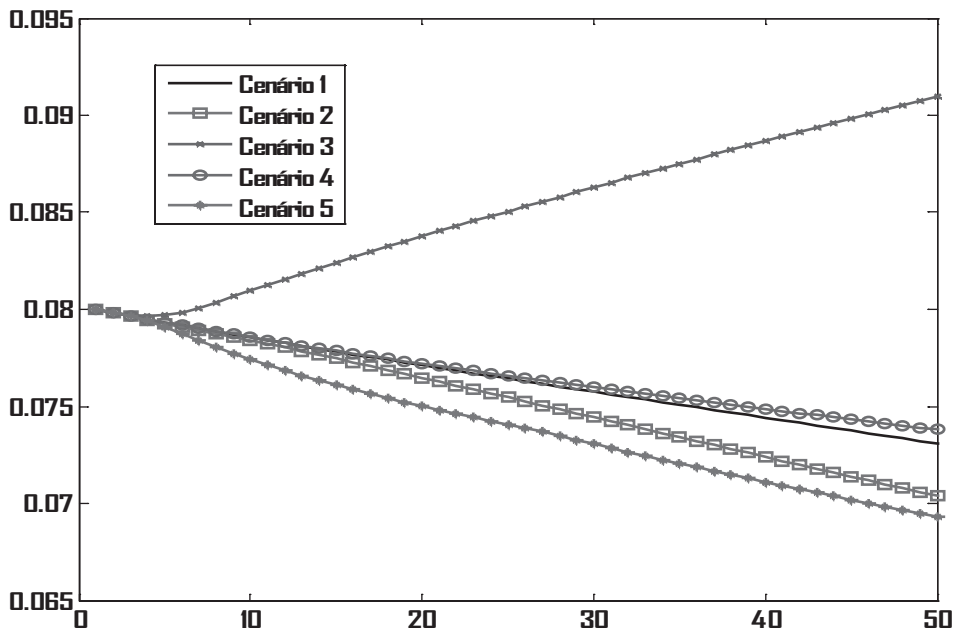

Figura 2 - Trajetória simulada do market share das exportações

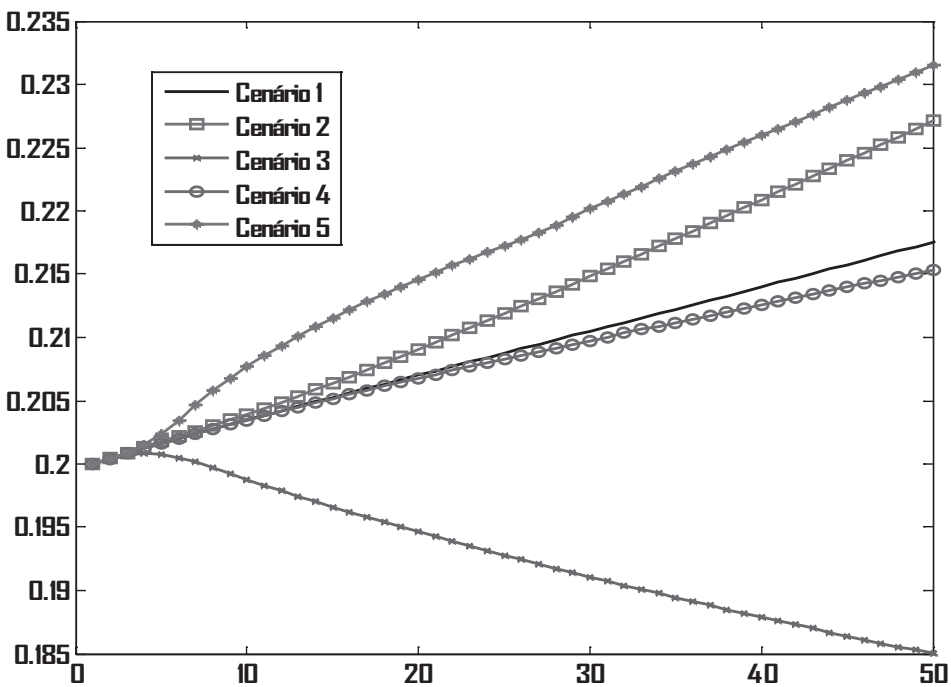

Figura 3 - Trajetória simulada do coeficiente de importação

Outro importante indicador de desempenho macroeconômico é o saldo do balanço de pagamento (\% sobre o PIB), cujas trajetórias simuladas estão sumarizadas na Figura 4. De acordo com essa figura, 
o saldo comercial foi afetado sobremaneira por alguns tipos de políticas redistributivas. O cenário representativo da política de transferência sem déficit favoreceu o aumento positivo do saldo comercial, ocorrendo tendência contrária no cenário representativo de política de transferência com déficit. Esse resultado sugere a ocorrência de "déficits gêmeos", mas a causa desse fenômeno no modelo pode ser entendida a partir da Figura 1. No primeiro cenário, a taxa de crescimento da economia diminui desde o momento em que ocorre a mudança. No segundo cenário, a taxa de crescimento expande nos primeiros períodos, aumentando o grau de utilização da capacidade produtiva com efeitos deletérios sobre a competitividade, o que tornou inevitável a redução do saldo comercial. Depois de implantadas as mudanças, os níveis de competitividade retornam aos patamares originais, estabilizando o saldo comercial.

Os resultados acima mostram que o Cenário 2, que representa uma política redistributiva de renda via transferência de renda sem déficit governamental, é pior quando se trata de crescimento, e um dos piores quando se trata de competitividade externa. No entanto, a situação das contas apresenta o melhor resultado nesse cenário. Por outro lado, no Cenário 3, que se refere a uma política de distribuição de renda sem transferência de renda do governo para as famílias, surge uma tendência de melhoria das contas externas.

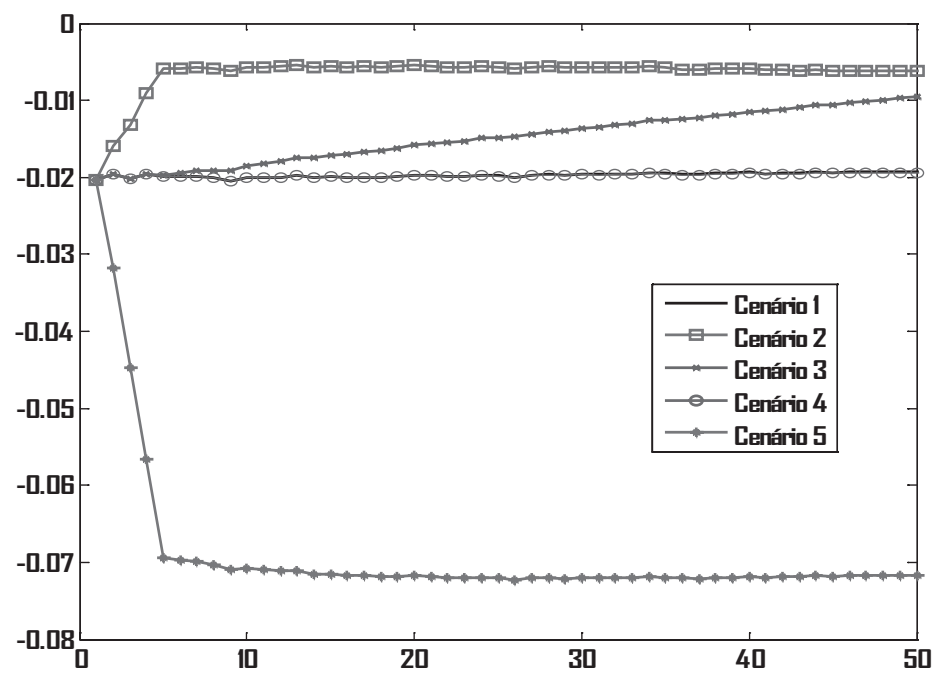

Figura 4 - Trajetória simulada do saldo em conta corrente 
O impacto das mudanças representadas nos cenários acima sobre as taxas de investimentos (líquidos) estão representados na Figura 5. Novamente, os Cenários 2 e 5 geram resultados antagônicos. Nos períodos em que são efetivadas as mudanças representadas nesses cenários ocorrem variações bruscas nesse indicador. No Cenário 2, essa taxa cai vertiginosamente nos primeiros períodos, elevando-se paulatinamente depois. Movimento contrário é observado no Cenário 5. Fica claro, portanto, que as mudanças representadas nesses cenários provocam desequilíbrios de natureza macroeconômica, impactando na tendência de crescimento de longo prazo. Nota-se que a mudança representada no Cenário 3 é a que mais impactou na tendência de crescimento, ao longo de todo o período de simulação, porém produzindo mudanças suaves (e positivas) na taxa de investimento.

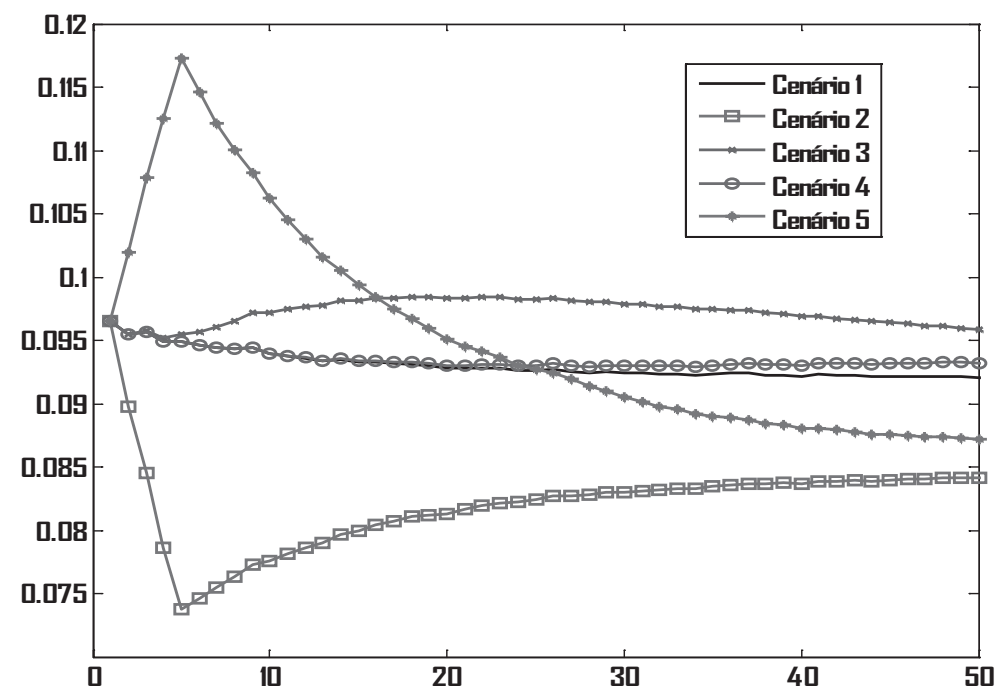

Figura 5 - Trajetória simulada da taxa de investimento

O impacto das mudanças representadas em cada cenário sobre os preços internos e sobre a competitividade externa pode ser avaliada por meio da Figura 6. O Cenário 5 se destaca pelo grande impacto sobre o grau de utilização da capacidade produtiva, atingindo patamar máximo (problemas de ajustamento na simulação com a presença de lags permitiu que a variável $u$ ultrapassasse o valor unitário), o que gerou pressões inflacionárias (Equação 22) e comprometeu a 
competitividade externa (Equação 16). No longo prazo, a perda de competitividade reduz o ritmo de crescimento da economia, diminuindo as pressões sobre o grau de utilização da capacidade produtiva. Tendências opostas são observadas no Cenário 2. A economia se desacelera nos primeiros períodos da simulação, reduzindo a taxa de investimento. Nos períodos seguintes, a taxa de investimento fica mantida em patamares inferiores aos demais cenários (Figura 5) por conta da redução da participação dos investimentos públicos, refletindo sobre o grau de ocupação da capacidade produtiva no restante do período de simulação, o qual permanece em nível acima dos demais cenários em boa parte do período de simulação.

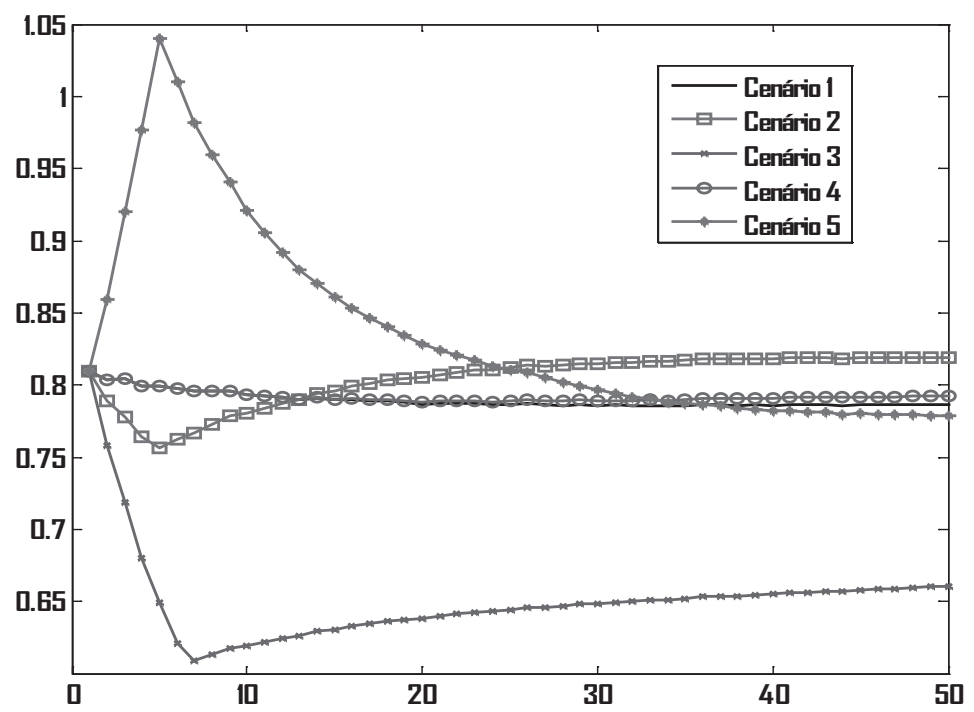

Figura 6 - Trajetória simulada do grau de utilização da capacidade produtiva

O exercício de simulação teve como ponto de partida a teoria estruturalista, de Fajnzylber (1989). O resultado indicou que nem todas as políticas que levam a maior equidade geram aumento na taxa de crescimento. O Cenário 2, em que há transferência de renda sem déficit público, foi o pior deles, ficando o crescimento de longo prazo abaixo do Cenário 1 (benchmark), que supôs não haver distribuição de renda. Outras variáveis como competitividade e nível de investimento também apresentaram resultados negativos. Por outro lado, 
o Cenário 3, no qual se supôs uma reforma - como aumento real do salário mínimo -, que leva a uma mudança na estrutura do consumo em favor de produtos cuja relação capital/produto é menor, foi o que apresentou um ciclo virtuoso do crescimento, como defendido por Fajnzylber. O aumento da capacidade produtiva, em função da queda da relação capital/produto, reduz o grau de utilização dessa capacidade, aumentando o nível de competitividade da economia, o que estimula novos investimentos. A taxa de crescimento do produto tende a crescer no longo prazo.

Vale notar que esse trade-off entre o curto e o longo prazos dos efeitos das políticas redistributivas sobre o crescimento econômico não é resultado inédito ou surpreendente. É fácil intuir que uma redistribuição de renda criada artificialmente por mecanismos fiscais, sem mudança estrutural, produz crescimento desequilibrado, o qual não se sustenta no longo prazo.

Diversos autores analisaram a relação entre o crescimento econômico e distribuição de renda numa perspectiva estruturalista. Esses autores são quase unânimes a respeito dos efeitos de longo prazo produzidos pela melhoria dos indicadores de distribuição de renda. Segundo Dutt (1990), o aumento da taxa de crescimento de longo prazo é fruto das relações de causalidades entre a propensão a consumir, a taxa de crescimento da economia e a taxa de investimento. Mudança estrutural na distribuição de renda eleva a propensão a consumir, aumentando o multiplicador de gastos, o que, por sua vez, gera a tendência de aumento do grau de utilização da capacidade produtiva, impactando diretamente as taxas de investimentos. Outro efeito comumente apontado é a mudança na composição dos gastos de consumo em direção aos setores menos intensivos em capital. Esse resultado é encontrado em Taylor (1979), Locatelli (1985) e Ribeiro (2012). Essa mudança eleva a proporção do emprego em relação à renda nacional, o que aumenta a propensão a consumir. Concomitantemente, a redução da relação capital/produto eleva a taxa de lucro, dando sustentação ou elevando a taxa de investimento (Barbosa-Filho, 2004). De acordo com essas análises, esses efeitos são suficientemente fortes para contrabalançar os efeitos negativos que, porventura, sejam produzidos por outros componentes endógenos da demanda final (importações, por exemplo). 
Ponderações para com essa perspectiva otimista emergem quando a redistribuição atinge patamares que comprometem a taxa de investimento em inovação (Lima, 2004) ou quando a redistribuição reduz a proporção dos gastos de consumo com serviços intensivos em mão de obra (Taylor, 1979). Por outro lado, quando o modelo é estendido com a endogeneização da competitividade externa, pode ocorrer ambiguidade nos resultados gerados pelos modelos. Se a redistribuição avançar além do patamar em que o aumento de produtividade não tenha força suficiente para contrabalançar o aumento dos custos de mão de obra, isso pode resultar em uma queda da taxa de crescimento das exportações e aumento do coeficiente de importação. Mas se essa redistribuição for fruto de investimento maciço em educação, com grande impacto sobre a oferta de mão de obra qualificada, isso pode resultar em atualização tecnológica (spillover), impactando diretamente sobre o desempenho externo (Landesmann e Stehrer, 2007).

Por conta do uso da simulação, foi possível explorar várias dimensões e feedbacks dos efeitos da redistribuição em um único modelo. Não obstante, os resultados desse modelo corroboram a ideia de um trade-off entre políticas de curto (não estruturantes) e de longo prazo (estruturantes). O resultado inédito está na conclusão de que entre as políticas redistributivas estruturantes a de melhor resultado não reside na de cunho educacional, mas naquela que melhora a participação do salário na renda nacional.

\section{Conclusões}

O exercício de simulação foi realizado com o propósito de analisar os efeitos das políticas de redistribuição de renda sobre a dinâmica do crescimento, com aplicação de algumas variáveis indicadoras do desempenho macroeconômico. Nesse exercício, foi utilizado um modelo de crescimento liderado pelas exportações, nos moldes sugeridos pelas abordagens kaldoriana e cepalina, particularmente de Fajnzylber. Para a execução dessa simulação, foram definidos cinco cenários.

Uma avaliação geral de todos os resultados indica que o cenário representativo dos efeitos do aumento dos salários na renda nacional 
apresentou o melhor desempenho macroeconômico, no longo prazo. Esse cenário se caracteriza pela manutenção de taxas de crescimento de longo prazo mais elevadas do que os demais cenários, além de maior nível de investimento e tendência crescente da competitividade. No entanto, a mudança representada pelo cenário em que há transferência de renda com déficit fiscal tem apelo político mais forte, pois gera resultados mais imediatos, sendo politicamente mais fácil de implementar. Essa conclusão compatibiliza-se com a realidade da economia brasileira durante o governo Lula, quando foram implementadas políticas redistributivas do tipo representada por esse último cenário. Nesse período, houve aumento das taxas de crescimento da economia (salvo momento atípico da crise de 2008), mas no final desse governo ocorre o esgotamento dessa tendência, com pressões inflacionárias.

Obviamente, a dinâmica do mundo real é muito mais complexa do que a dinâmica do modelo. Não obstante, o modelo foi capaz de gerar uma evolução macroeconômica, teoricamente semelhante à evolução da economia brasileira, a partir do momento em que foi efetivamente implementada uma política de redistribuição de renda apoiada na transferência de renda do governo com déficit fiscal: uma fase inicial com aumento significativo das taxas de crescimento, desdobrando-se em pressões inflacionárias, queda da taxa de investimento e perda da competitividade externa. Desse exercício de simulação, pode-se inferir que objetivos de curto prazo nem sempre podem ser compatibilizados com os de longo prazo.

O ideal, portanto, é entender esse modelo como uma tentativa embrionária de avaliar os efeitos das políticas de redistribuição de renda sobre a dinâmica do crescimento em um contexto teórico dominado pelas abordagens de natureza estruturalista, em especial a cepalina e a kaldoriana.

Pretende-se, futuramente, dar continuidade a essa linha de pesquisa, desagregando mais os setores produtivos, de modo a ter uma ideia mais precisa dos impactos das políticas distributivas da renda sobre a estrutura econômica. Também, pretende-se refinar o modelo, considerando-se outras variáveis, como efeitos de alteração da produtividade sobre as variáveis macroeconômicas. 


\section{Referências}

AGHION, P.; ALESINA, A.; TREBBI, F. Democracy, technology, and growth. Working Paper NBER, 13180. Cambridge: NBER. 2007.

AGHION, P.; CAROLI, E.; GARCIA-PEÑALOSA, C. Inequality and economic growth: the perspective of new growth theories. Journal of Economic Literature, v. 37, p. 1615-1661, dec., 1999.

BARBOSA-FILHO, N. H. A simple model of demand-led growth and income distribution. Revista Economia, v. 5, n. 3, p 117-154. 2004.

BIELSCHOWSKY, R. Cinquenta anos de pensamento da CEPAL. Rio de Janeiro: Record, 2004, v. 1 e 2.

BIELSCHOWSKY, R. Sesenta aõs de la CEPAL. Buenos Aires: Siglo Veintiuno, 2010.

BOCCANFUSO, D.; DECALUWÉ, B.; SAVARD, L. Poverty, income distribution and CGE microsimulation modeling: does the functional form of distribution matter? Journal of Economic Inequality, v. 6, 2007, p. 149-184.

BONELLI, R. e RAMOS, L. Distribuição de renda no Brasil: avaliação das tendências de longo prazo e mudanças na desigualdade desde os anos 70. Revista de Economia Política, v. 13, n. 2, 1993, p. 77-97.

BOURGUIGNON, F.; BRANSON, W. H.; MELO, J. Adjustment and Income Distribution: A Counterfactual Analysis. NBER Working Paper Series, n. 2943, 1989.

CAMPANO, F.; SALVATORE, D. Economic development and income distribution. Journal of Policy Modeling, v. 29, 2007, p. 553-556.

DEININGER, K.; SQUIRE, L. Economic Growth and income inequality: reexamining the links. Finance \& Development, 1997.

DUTT, A. K. Growth, distribution, and uneven development. New York. Cambridge University Press. 1990.

FAJNZYLBER, F. Industrializacion en America Latina: de la "caja negra” al "casillero vacio". Santiago de Chile: Naciones Unidas, 1989.

FURTADO, C. A economia latino-americana. São Paulo: Nacional, 1976.

FURTADO, C. Subdesenvolvimento e estagnação na América Latina. Rio de Janeiro: Civilização Brasileira, 1968.

GREENWOOD, J.; JOVANOVIC, B. Financial Development, Growth, and the Distribution of Income. The Journal of Political Economy, v. 98, n. 5, 1990, p. 1076-1107.

GREMAUD, A. P; SAES, F. M. S.; TONETO JR., R. Formação econômica do Brasil. São Paulo: Atlas, 1997.

JEONG, H.; TOWSEND, R. M. Growth and inequality: model evaluation based on an estimation-calibration strategy. Macroeconomic Dynamics, 12 (Supplement 2), 2008, p. 231-284.

KALDOR, N. Alternative Theories of Distribution. The Review of Economic Studies, v. 23, n.2, 1956, p. 83-100.

KUZNETS, S. Economic Growth and Income Inequality. The American Economic Review, v.45, n.1, p. 1-28, Mar. 1955.

LANDESMANN, M. A.; STEHRER, R. Income distribution, technical change and the dynamics of international economic integration. Metroeconomica, v. 58, n.1. 2007.

LANGONI, C. G. Distribuição de renda e desenvolvimento econômico do Brasil. Rio de Janeiro: Expressão e Cultura, 1973.

LIMA, G. T. Endogenous technological innovation, capital accumulation and distribution dynamics. Metroeconomica, v. 55, n. 4. 2004. 
LIMA, G. T. Progresso tecnológico endógeno, crescimento econômico e distribuição de renda. In: LIMA, G. T; SICSÚ, J.; PAULA, L. F. (Orgs). Macroeconomia moderna: Keynes e a economia contemporânea. Rio de Janeiro: Campus, 1999.

LOCATELLI, R. L. Efeitos macroeconômicos de uma redistribuição de renda: um estudo para o Brasil. Pesquisa e Planejamento Econômico, v.15, n.1, p.139-170, 1985.

MOREIRA, G. R.C.; ALMEIDA, L.; GUILHOTO, J. M.; AZZONI, C.R. Productive structure and income distribution: the Brazilian case. The Quarterly Review of Economics and Finance, v. 48, 2008, p. 320-332.

MORLEY, S. The income distribution problem in Latin América and the Caribbean. Santiago: CEPAL, 2001. 169 p.

PASINETTI, L. Rate of profit and Income Distribution in Relation to the Rate of Economic Growth, Review of Economic Studies, v. 29, n. 81, oct. 1962, p. 267-279.

PREBISCH, R. O desenvolvimento econômico da América Latina e alguns de seus problemas principais. In: BIELSCHOWSKY (Ed.). Cinquenta anos de pensamento da CEPAL. Record: Rio de Janeiro, 2000.

RIBEIRO, G. M. Efeitos da distribuição sobre o nível de renda da economia: uma análise da composição setorial produtiva do Brasil. 2012. 66 p. Dissertação (Mestrado em Economia) - Departamento de Economia, Universidade Federal de Viçosa, Viçosa. 2012.

ROBERTS, B. M.; ZOLKIEWSKI, Z. Modelling income distribution in countries in transition: a computable general equilibrium analysis for Poland. Economic Modelling, v. 13, 1996, p. 67-90.

ROBINSON, J. The accumulation of capital. London: Macmillan, 1956.

TAVARES, M. C. Da substituição de importações ao capitalismo financeiro. Rio de Janeiro: Zahar, 1982.

TAYLOR, L. Macro models for developing countries. New York: MacGraw-Hill. 1979.

WANG, Z.; ZHAI, F. Tariff reduction, tax replacement, and implications for income distribution in China. Journal of Comparative Economics, v. 26, 1998, p. 358-387.

WORLD BANK. World Development Report: Equit and Development. Washington: World Bank, 2006. 


\section{ANEXO A - Valores iniciais e dos parâmetros}

\begin{tabular}{|lc|}
\hline Parâmetros - Valores & Equação \\
$b_{l}=0.8$ & 2 \\
$b_{2}=0.8$ & 4 e 5 \\
$v=0.15$ (valor inicial) & 3 \\
$s=0.08$ (valor inicial) & 6 \\
$m=0.2$ (valor inicial) & 7 \\
$\alpha_{k}=0.01$ & 8 \\
$t=0.35$ & 9 \\
$\bar{u}=0.8$ & 8 \\
$\sigma=0.5$ & 11 \\
$\delta=0.05$ & 12 \\
$\phi i=0.01$ & $13 \mathrm{e} 14$ \\
$\beta i=0.5$ & 16 \\
$\alpha=0.01$ & 22 \\
$\hat{Y}^{m}=0.04$ & 19 \\
$\hat{X}^{m}=0.04$ (implícito) & 22 \\
$\beta_{i}=0.5$ & 6 \\
$\Theta=1$ & 16 \\
$\rho=0.01$ & 20 \\
$\gamma_{i}=100$ & 23 \\
$j=0.1$ & 25 \\
$\bar{J}=0.03$ & 25 \\
\hline & 25 \\
\hline
\end{tabular}

\section{ANEXO B - Teste de robustez do modelo}

A robustez do modelo foi testada com o método de Monte Carlo (software SIMULINK/MATLAB), aplicando-se uma distribuição uniforme com 20 extrações para cada parâmetro. Os intervalos máximos e mínimos dos valores extraídos foram definidos nos seguintes termos:

a) De 0,2 a 1 para os parâmetros $b_{1}$ e $b_{2}$;

b) De 0 a 1 para os parâmetros $\beta_{1}, \beta_{2}$ e $\beta_{3}$ (conjuntos diferentes para as equações de exportação, equação 13 , e de importação, equação 14);

c) De 0 a 0,1 para os parâmetros $a_{k}, \phi_{i}, \alpha, \rho, \hat{Y}^{m}$ e $\hat{X}^{m}$;

d) De 0 a 1.000 para os parâmetros $\gamma_{i}$. 
As variáveis selecionadas para avaliar a qualidade do modelo e seus respectivos valores máximos e mínimos estão registradas na Tabela 2. Entre elas, a variável $u$ foi a que apresentou resultados menos satisfatórios no que se refere a sua média e a seu valor mínimo. Provavelmente, isso reflete o fato de que a maioria dos valores iterados para os parâmetros $b_{1}$ e $b_{2}$ ficaram abaixo de 0,6 , o que reduziu o efeito multiplicador do modelo. Além disso, em seus valores mais elevados, essa variável não ultrapassou 0,8 , considerado o nível teoricamente normal de $u$.

Tabela 1 - Valores máximos, mínimos, médios e desvio-padrão em distribuição uniforme dos parâmetros submetidos ao método Monte Carlo

\begin{tabular}{|c|c|c|c|c|}
\hline Parâmetros & Máximo & Mínimo & Média & Desvio-Padrão \\
$b_{1}$ & 0,876 & 0,119 & 0,506 & 0,24 \\
$b_{2}$ & 0,968 & 0,295 & 0,605 & 0,192 \\
$a_{k}$ & 0,0959 & 0,0139 & 0.0506 & 0.0286 \\
$\phi_{i}$ (exportação) & 0,0971 & 0,00975 & 0,0642 & 0,033 \\
$\beta_{1}$ (exportação) & 0,971 & 0.0975 & 0,642 & 0,33 \\
$\beta_{2}$ (exportação) & 0,95 & 0,0318 & 0,493 & 0,334 \\
$\beta_{3}$ (exportação) & 0,96 & 0,119 & 0,506 & 0,24 \\
$\phi_{i}$ (importação) & 0,0959 & 0,0139 & 0,0506 & 0,0286 \\
$\beta_{1}$ (importação) & 0,95 & 0,0318 & 0,493 & 0,334 \\
$\beta_{2}$ (importação) & 0,971 & 0,0975 & 0,642 & 0,33 \\
$\beta_{3}$ (importação) & 0,96 & 0,119 & 0,506 & 0,24 \\
$\rho$ & 0,0962 & 0,000463 & 0,0465 & 0,0332 \\
$\hat{Y}^{m}$ & 0,076 & 0,00255 & 0,0394 & 0,0268 \\
$\hat{X}^{m}$ & 0,0776 & 0,0078 & 0,0514 & 0,0264 \\
$\gamma_{1}$ & 971 & 97,5 & 642 & 330 \\
$\gamma_{2}$ & 950 & 31,8 & 493 & 334 \\
$\gamma_{3}$ & 119 & 506 & 240 \\
\hline & 060 & & \\
\hline
\end{tabular}


Tabela 2 - Valores máximos, mínimos, médios e desvio-padrão das variáveis selecionadas para avaliar resultados do teste

\begin{tabular}{|c|c|c|c|c|}
\hline Variáveis & Máximo & Mínimo & Média & Desvio- Padrão \\
$\hat{Y}$ & 0,077 & $-0,195$ & $-0,0185$ & 0,0347 \\
$v$ & 0,152 & 0,0102 & 0,0976 & 0,0404 \\
$s$ & 0,107 & 0,000638 & 0,0399 & 0,0294 \\
$m$ & 0,993 & 0,161 & 0,565 & 0,262 \\
$u$ & 0,748 & 0 & 0,0269 & 0,169 \\
$\mathrm{R}(\%$ do PIB $)$ & 0,524 & $-0,0705$ & 0,154 & 0,183 \\
\hline
\end{tabular}

